\title{
Sympathetic Activity Controls Fat-Induced Oleoylethanolamide Signaling in Small Intestine
}

\author{
Jin Fu, ${ }^{1 \star}$ Nicholas V. DiPatrizio, ${ }^{1 \star}$ Ana Guijarro, ${ }^{1}$ Gary J. Schwartz, ${ }^{2,3,4}$ Xiaosong Li, ${ }^{2,3,4}$ Silvana Gaetani, ${ }^{5}$ \\ Giuseppe Astarita, ${ }^{1}$ and Daniele Piomelli ${ }^{1,6}$ \\ ${ }^{1}$ Department of Pharmacology, School of Medicine, University of California, Irvine, Irvine, California 92697-4625, ${ }^{2}$ Diabetes Research Center and \\ Departments of ${ }^{3}$ Medicine and ${ }^{4}$ Neuroscience, Albert Einstein College of Medicine of Yeshiva University, Bronx, New York 10461, ${ }^{5}$ Department of \\ Physiology and Pharmacology "V. Erspamer," Sapienza University of Rome, 00185 Rome, Italy, and 'Unit of Drug Discovery and Development, Italian \\ Institute of Technology, 16163 Genoa, Italy
}

Ingestion of dietary fat stimulates production of the small-intestinal satiety factors oleoylethanolamide (OEA) and $N$-palmitoylphosphatidylethanolamine (NPPE), which reduce food intake through a combination of local (OEA) and systemic (NPPE) actions. Previous studies have shown that sympathetic innervation of the gut is necessary for duodenal infusions of fat to induce satiety, suggesting that sympathetic activity may engage small-intestinal satiety signals such as OEA and NPPE. In the present study, we show that surgical resection of the sympathetic celiac-superior mesenteric ganglion complex, which sends projections to the upper gut, abolishes feeding-induced OEA production in rat small-intestinal cells. These effects are accounted for by suppression of OEA biosynthesis, and are mimicked by administration of the selective $\beta_{2}$-adrenergic receptor antagonist ICI-118,551. We further show that sympathetic ganglionectomy or pharmacological blockade of $\beta_{2}$-adrenergic receptors prevents NPPE release into the circulation. In addition, sympathetic ganglionectomy increases meal frequency and lowers satiety ratio, and these effects are corrected by pharmacological administration of OEA. The results suggest that sympathetic activity controls fat-induced satiety by enabling the coordinated production of local (OEA) and systemic (NPPE) satiety signals in the small intestine.

\section{Introduction}

The lipid-derived satiety factors, oleoylethanolamide (OEA) (Rodríguez de Fonseca et al., 2001; Fu et al., 2007) and N-palmitoylphosphatidylethanolamine (NPPE) (Gillum et al., 2008), are critically involved in the regulation of fat intake. These substances are produced in the proximal small intestine after ingestion of dietary fat and exert their anorectic effects through seemingly distinct physiological mechanisms (Rodríguez de Fonseca et al., 2001; Fu et al., 2007; Gillum et al., 2008; Schwartz et al., 2008). Evidence indicates that OEA operates as a local messenger within the gut and promotes satiety by recruiting afferent fibers of the vagus nerve (Rodríguez de Fonseca et al., 2001; Gaetani et al., 2003; Proulx et al., 2005; Fu et al., 2007, 2008), whereas NPPE is thought to act as a blood-borne hormone and to reduce food intake by direct activation of neuronal circuits in the hypothalamus (Gillum et al., 2008).

The biochemical pathways underlying the production of OEA and NPPE also appear to be markedly different. OEA biosynthe-

\footnotetext{
Received Oct. 28, 2010; revised Feb. 1, 2011; accepted Feb. 22, 2011

Author contributions: J.F., N.V.D., G.J.S., S.G., and D.P. designed research; J.F., N.V.D., A.G., G.J.S., X.L., and G.A. performed research; J.F., N.V.D., and A.G. analyzed data; N.V.D. and D.P. wrote the paper.

The support of the Agilent/University of California, Irvine Analytical Research Facility is gratefully acknowledged. This study was supported by National Institutes of Health Grants DK073955 (D.P.) and DK047208 (G.J.S.), the Skirball Institute, the New York Obesity Research Center (NIH5P30DK026687), and Italian Ministry of Research PRIN Grant 2007 (S.G.).

*J.F. and N.V.D. contributed equally to this work.

Correspondence should be addressed to Daniele Piomelli, Department of Pharmacology, University of California, Irvine, 3101 Gillespie Neuroscience Research Facility, Irvine, CA 92697-4625. E-mail: piomelli@uci.edu. DOI:10.1523/JNEUROSCI.5668-10.2011

Copyright $\odot 2011$ the authors $\quad 0270-6474 / 11 / 315730-07 \$ 15.00 / 0$
}

sis in response to dietary fat occurs primarily, if not exclusively, in absorptive epithelial cells of the duodenum and jejunum (Fu et al., 2007; Gillum et al., 2008; Schwartz et al., 2008). These cells use food-derived oleic acid to generate the phospholipid $\mathrm{N}$-oleoylphosphatidylethanolamine (NOPE), which is then cleaved by $N$-acyl-phosphatidylethanolamine-selective phospholipase D (NAPEPLD) to release OEA (Fig. 1) (Fu et al., 2007; Schwartz et al., 2008). OEA-mediated signaling at peroxisome proliferator-activated receptors type $\alpha$ (Fu et al., 2003) engages vagal afferents in the gut to promote satiety (Rodríguez de Fonseca et al., 2001) and is terminated by OEA hydrolysis (Fig. 1) (Fu et al., 2007). Small-intestinal NPPE biosynthesis is also stimulated by dietary fat (Gillum et al., 2008), but is not dependent on food-derived oleic acid, and its precise regulation is still unknown (Fig. 1) (Fu et al., 2007; Schwartz et al., 2008).

An important question that remains to be addressed is whether the nervous system participates in the control of OEAand NPPE-mediated signaling. The sympathetic division of the autonomic nervous system, in particular, is likely to play a role in this process. Sympathetic preganglionic neurons synapse at prevertebral ganglia, forming the celiac-superior mesenteric ganglion complex, which sends noradrenergic projections to multiple visceral organs, including the intestine (Lindh et al., 1988; Chevendra and Weaver, 1991; Parr et al., 1993; Furness et al., 2000; Nasser et al., 2006). Surgical removal of this complex impairs the ability of intraduodenal infusions of fat to reduce food intake, which suggests that the outflow of sympathetic nerves to the gut may contribute to fat-induced satiety (Sclafani et al., 2003). More- 


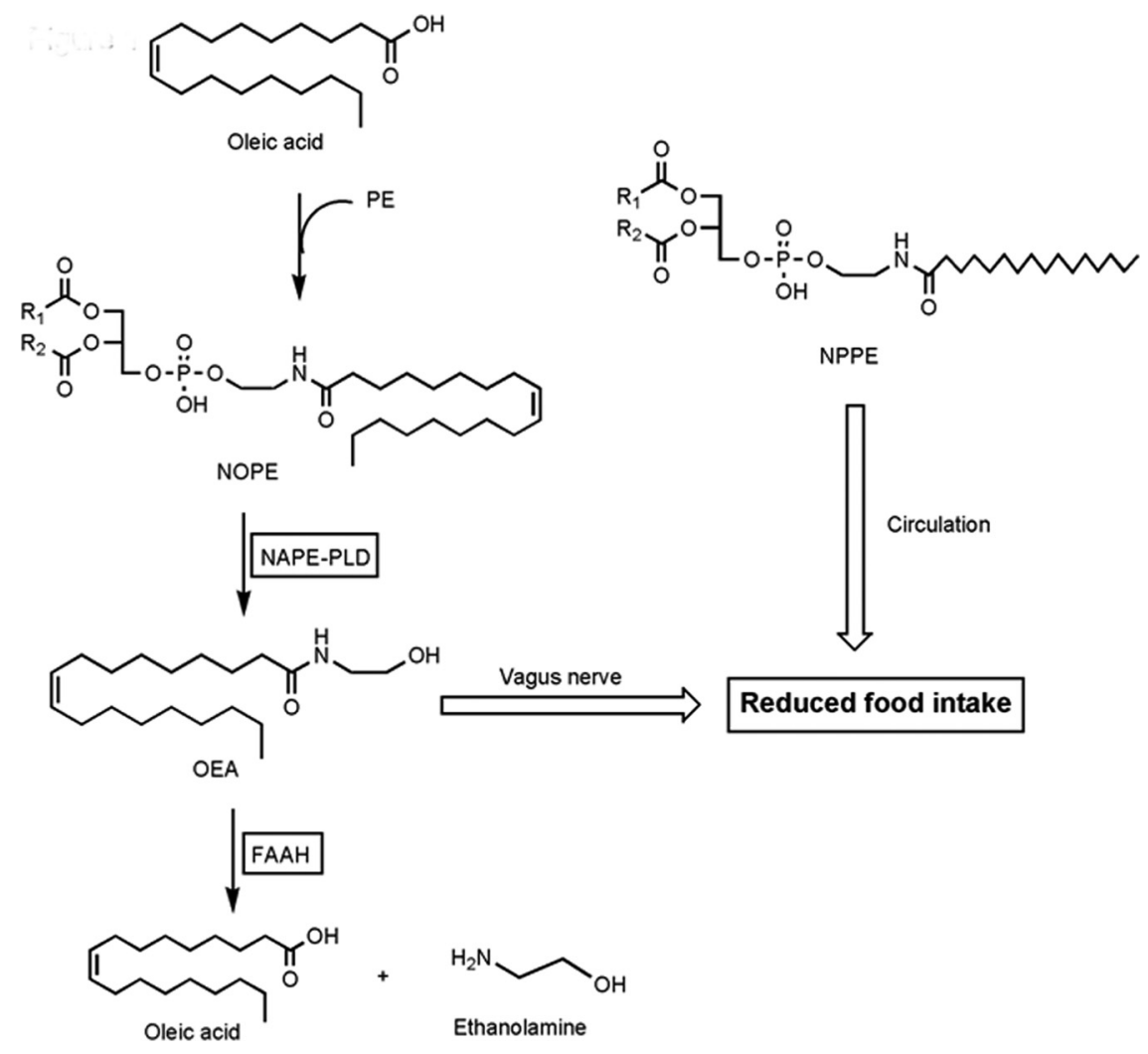

Figure 1. Diagram illustrating OEA and NPPE metabolism in rodent small intestine. Enterocytes in duodenum and jejunum incorporate food-derived oleic acid into the phospholipid NOPE (Schwartz et al., 2008). Newly formed NOPE is hydrolyzed by NAPE-PLD to yield OEA (Schwartz et al., 2008). OEA signaling is terminated by enzyme-mediated hydrolysis, which is primarily catalyzed by FAAH (Fu et al., 2007). Dietary fat stimulates the small-intestinal mobilization of NPPE through a mechanism that remains to be elucidated. Newly formed NPPE is released into the lymphatic system and reaches the brain via the general circulation (Gillum et al., 2008).

over, previous work from our laboratory has shown that sympathetic activation stimulates OEA biosynthesis in rat white adipose tissue (LoVerme et al., 2006). In the present study, we have used a combination of surgical and pharmacological approaches to examine whether sympathetic activity is implicated in the control of OEA and NPPE mobilization in the rat small intestine.

\section{Materials and Methods}

Animals

A total of 205 adult male Sprague Dawley rats (250-300 g) were purchased from Charles River and housed in standard cages (four per cage) at room temperature $\left(22^{\circ} \mathrm{C}\right)$. They were maintained on a $12 \mathrm{~h} \mathrm{light/dark}$ cycle (on at 6:30 A.M., off at 6:30 P.M.) and had ad libitum access to water and standard chow pellets (Research Diets), unless otherwise noted. When experimentation began, the rats were housed individually in suspension cages consisting of wire bottoms to prevent coprophagia, and habituated to the experimental settings for $4 \mathrm{~d}$. All procedures met the National Institutes of Health guidelines for the care and use of laboratory animals, and were approved by the Institutional Animal Care and Use Committee of the University of California, Irvine.

\section{Chemicals}

Prazosin, CGP20712A, SR59230A, ICI-118,551, isoproterenol, and salbutamol were purchased from Sigma-Aldrich. Drugs were prepared at concentrations that allowed administration in $2 \mathrm{ml} / \mathrm{kg}$ of an appropriate vehicle (described below). 1,2-Dipalmitoyl-sn-glycero-3-phosphoethanolamine was from Sigma and $\left[{ }^{3} \mathrm{H}\right]$-anandamide (arachidonoyl-1- $\left[{ }^{3} \mathrm{H}\right]$ ethanolamide) from American Radiolabeled Chemicals. $\left[{ }^{2} \mathrm{H}_{4}\right]$-OEA, 1,2-dipalmitoyl-snglycero-3-phosphoethanolamine- $N$-heptadecanoyl, and 1,2-dipalmitoyl$s n$-glycero-phosphoethanolamine- $N$-heptadecenoyl were synthesized in the laboratory (Fu et al., 2007) using appropriate fatty acid chlorides purchased from $\mathrm{Nu}-\mathrm{Chek}$ Prep.

\section{Surgical procedures}

Resection of the celiac-superior mesenteric ganglion complex was performed as previously described (Sclafani et al., 2003). In brief, animals were anesthetized with an intraperitoneal injection of ketamine $(100 \mathrm{mg} / \mathrm{kg})$ and xylazine $(10 \mathrm{mg} / \mathrm{kg})$. A midline incision was made through the skin and abdominal muscle, and the stomach and spleen were exposed and gently retracted. The descending aorta was visualized, and the ganglion complex was isolated with fine forceps and severed for removal using microsurgical scissors. Care was taken not to damage the adjacent celiac and superior mesenteric arteries. The abdominal muscle wall was closed using plain gut 4-0 suture ( $\mathrm{Fi}-$ scher Scientific) and the skin sutured using stainless steel wound clips. Sham-operated control animals underwent the same procedure, except that the sympathetic ganglion complex was left intact. For pain management, animals received buprenorphine $(0.02 \mathrm{mg} / \mathrm{kg}$, i.p.) just before and following surgery. Testing started $7 \mathrm{~d}$ after surgery. Following experimentation, verification of correct ganglionectomy was made by determining the absence of neural tissue at the level of the celiac and mesenteric artery branching at the descending aorta (see Fig. 2E,F).

\section{Experimental design}

Effects of celiac superior mesenteric ganglionectomy. Forty-eight rats were randomized into four groups of ganglionectomized and shamoperated $(n=12$ for each surgery condition for rats refed standard rodent chow, and $n=12$ for each surgery condition for rats refed a high-fat diet; experimentation on groups receiving different diets occurred on separate days). Seven days after surgery, each group was further divided into two subgroups: fooddeprived rats $(n=6)$, which had no access to food for $24 \mathrm{~h}$, and refed rats $(n=6)$, which were allowed to eat standard rodent chow or the high-fat diet for $30 \mathrm{~min}$ following a $24 \mathrm{~h}$ fast. All animals within a diet group were killed at the same time.

Effects of adrenergic receptor antagonists. Each receptor antagonist was tested on a separate group of 24 rats. The animals were randomized into two groups: food-deprived $(n=12)$ and refed $(n=12)$ (see above). Each group was further divided into a vehicle subgroup $(n=6)$, which received $2 \mathrm{ml} / \mathrm{kg}$ dimethylsulfoxide (30\% in saline), and a drug subgroup $(n=6)$, which received one of the following antagonists: CGP2071 $\left(\beta_{1}\right.$ receptor; $1 \mathrm{mg} / \mathrm{kg})$, ICI-118,551 ( $\beta_{2}$ receptor; $\left.1 \mathrm{mg} / \mathrm{kg}\right)$, SR59230A $\left(\beta_{3}\right.$ receptor; $1 \mathrm{mg} / \mathrm{kg}$ ), or prazosin ( $\alpha$ receptor; $5 \mathrm{mg} / \mathrm{kg}$ ). Vehicle or drugs were administered by intraperitoneal injection $30 \mathrm{~min}$ before tissue collection (jejunum, blood).

Effects of $\beta$-adrenergic receptor agonists. Thirty-six food-deprived animals were divided into three groups: vehicle $(n=6)$, which received an intraperitoneal injection of saline $(2 \mathrm{ml} / \mathrm{kg})$; isoproterenol $\left(\beta_{1} / \beta_{2}\right.$ receptors; $2.5,5,10 \mathrm{mg} / \mathrm{kg}, n=6$ per dose); and salbutamol ( $\beta_{2}$ receptors; 1 or $5 \mathrm{mg} / \mathrm{kg}, n=6$ per dose). Six free-feeding animals were also included. Drugs were administered by intraperitoneal injection $30 \mathrm{~min}$ before tissue collection (jejunum).

\section{Feeding behavior}

Animals ( 9 sham-operated rats and 10 ganglionectomized rats) were habituated to the test cages for $3 \mathrm{~d}$ before trials. Feeding behavior was analyzed in rats starting at the onset of the dark phase (6:45 P.M.) and lasting for $24 \mathrm{~h}$. Free feeding was analyzed for 5 consecutive days, and the 
average of these five trials was calculated for each parameter. Food intake was recorded using the automated system TSE Drinking \& Feeding Monitor (TSE Technical \& Scientific Equipment). This system consists of cages equipped with baskets filled with standard chow pellets and connected to weight sensors that record the duration of each meal (each time food is taken from the basket), the quantity of food consumed, and the time at which the event occurred. Weight variations were monitored every second, and the threshold for an eating episode was set at $0.6 \mathrm{~g}$ and $>1$ min. Feeding parameters (Gaetani et al., 2003) were divided into the following categories: average meal frequency (meals/h), average meal size $(\mathrm{g} / \mathrm{kg})$, average postmeal interval (PMI; min), average satiety ratio [SR; ratio between average $\mathrm{PMI}$ and meal size, $\mathrm{min} /(\mathrm{g} / \mathrm{kg})]$. Feeding data were analyzed as total food ingested per kilogram of body weight and as cumulative food intake $(\mathrm{g} / \mathrm{kg})$ over $24 \mathrm{~h}$. The significance of differences between sham-operated and ganglionectomized rats were analyzed by Student's $t$ test.

\section{Lipid extractions}

Animals were anesthetized with isoflurane, and the jejunum was rapidly removed, snap-frozen in liquid $\mathrm{N}_{2}$, and stored at $-80^{\circ} \mathrm{C}$ until analyses. Blood was collected via cardioventricular puncture in heparin-containing vials and centrifuged at $2000 \times g$ for 30 min to obtain plasma. Samples of jejunal tissue were homogenized in $1 \mathrm{ml}$ of methanol containing $\left[{ }^{2} \mathrm{H}_{4}\right]$ OEA as internal standard. Lipids were extracted with chloroform (2 vol), and the extracts were washed with water $(1 \mathrm{vol})$. Organic phases were collected and dried under $\mathrm{N}_{2}$. OEA, NOPE, and NPPE were fractionated by open-bed silica gel column chromatography, as previously described (Astarita et al., 2009). Eluted fractions were dried under $\mathrm{N}_{2}$ and reconstituted in $60 \mathrm{ml}$ of methanol for analyses.

\section{Liquid chromatography/mass spectrometry analyses}

We used an 1100-LC system coupled to a 1946D-MS detector (Agilent Technologies) equipped with an electrospray ionization interface. Lipids were separated on a XDB Eclipse $\mathrm{C}_{18}$ column $[50 \times 4.6 \mathrm{~mm}$ inner diameter (i.d.), $1.8 \mu \mathrm{m}$, Zorbax], eluted by a gradient of methanol in water (from $85 \%$ to $90 \%$ methanol in $2.5 \mathrm{~min}$ ) at a flow rate of $1.5 \mathrm{ml} / \mathrm{min}$. Column temperature was kept at $40^{\circ} \mathrm{C}$. Mass spectrometry (MS) detection was in the positive ionization mode, capillary voltage was set at $3 \mathrm{kV}$, and fragmenter voltage at $120 \mathrm{~V}$. Lipids were quantified with an isotope-dilution method (Giuffrida et al., 2000), monitoring sodium adducts of the molecular ions $[\mathrm{M}+\mathrm{Na}]^{+}$in the selected ion-monitoring (SIM) mode (Fu et al., 2007). For NOPE and NPPE analysis, we used a Poroshell 300 SB C $_{18}$ column ( $2.1 \times 75 \mathrm{~mm}$ i.d., $5 \mu \mathrm{m}$, Agilent) eluted with a linear gradient of methanol in water containing $5 \mathrm{~mm}$ ammonium acetate and $0.25 \%$ acetic acid (from $85 \%$ to $100 \%$ in $4 \mathrm{~min}$ ), at a flow rate of $1 \mathrm{ml} / \mathrm{min}$. NOPE and NPPE were identified using an Ion Trap XCT (Agilent) system in the negative ionization mode; the capillary voltage was set at $4.5 \mathrm{kV}$, the skim 1 at $-40 \mathrm{~V}$, and the capillary exit at $-151 \mathrm{~V}$. NOPE and NPPE were identified by their retention times and liquid chromatography (LC)/MS ${ }^{\mathrm{n}}$ properties as described previously (Fu et al., 2007). Extracted ion chromatograms were used to quantify each precursor ion by selecting two or more characteristic product ions: 1-stearoyl-2-arachidonoyl-sn-glycero-phosphoethanolamine- $N$-oleoyl (for NOPE), 1-stearoyl-2-arachidonoyl-sn-glycero-phosphoethanolamine- $N$ palmitoyl (for NPPE), and 1,2-dipalmitoyl-sn-glycero-3-phosphoethanolamine- $N$-heptadecanoyl, which was used as an internal standard (Fu et al., 2007).

\section{NAPE-PLD assay}

Jejunal tissue was homogenized in ice-cold Tris- $\mathrm{HCl}$ (50 mm, pH 7.5, 10 $\mathrm{vol})$ containing $0.32 \mathrm{M}$ sucrose. Homogenates were centrifuged at $1000 \times$ $g$ for $10 \mathrm{~min}$, and the supernatants ( $0.1 \mathrm{mg}$ of protein) were incubated at $37^{\circ} \mathrm{C}$ for $30 \mathrm{~min}$ in Tris- $\mathrm{HCl}(50 \mathrm{~mm}, \mathrm{pH} 7.4,0.2 \mathrm{ml})$ containing $0.1 \%$ Triton X-100, phenylmethylsulfonylfluoride (1 mM) and 1,2-dipalmitoylsn-glycero-3-phosphoethanolamine- $N$-heptadecenoyl $(0.1 \mathrm{~mm})$. Reactions were stopped by adding $0.6 \mathrm{ml}$ of chloroform-methanol $(2: 1, \mathrm{v} / \mathrm{v})$ containing $\mathrm{N}$-heptadecenoyl- $\left[{ }^{2} \mathrm{H}_{4}\right]$-ethanolamide as internal standard. After centrifugation at $1000 \times g$ at $4^{\circ} \mathrm{C}$ for $10 \mathrm{~min}$, the organic layers were collected and dried under $\mathrm{N}_{2}$. The residues were suspended in $50 \mu \mathrm{l}$ of chloroform/methanol $(1: 3, \mathrm{v} / \mathrm{v})$ and analyzed by LC/MS. We quantified $\mathrm{N}$-heptadecenoylethanolamide with an isotope-dilution method,
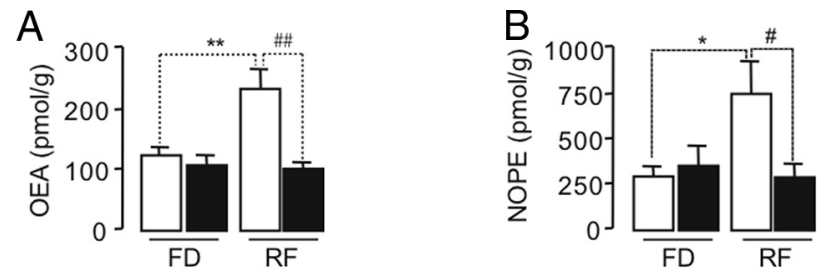

C

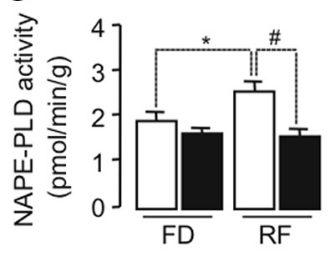

D
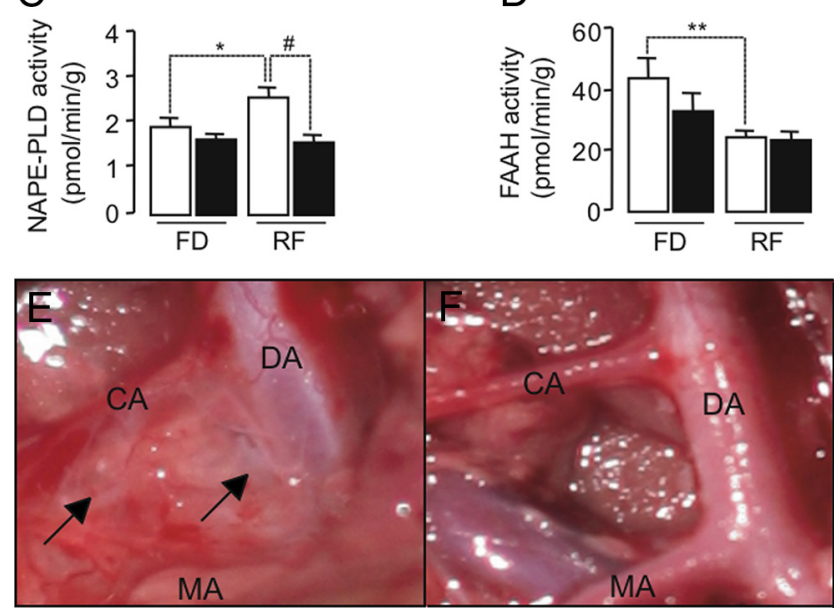

Figure 2. Sympathetic denervation abolishes feeding-induced OEA mobilization in rat proximal small intestine. Effects of $30 \mathrm{~min}$ refeeding after $24 \mathrm{~h}$ food deprivation (RF) or food deprivation alone (FD) on jejunal levels of OEA $(\boldsymbol{A}), \operatorname{NOPE}(\boldsymbol{B})$, NAPE-PLD activity $(\boldsymbol{C})$, and FAAH activity (D) in sham-operated (open bars) or ganglionectomized (filled bars) rats. Photomicrographs represent an intact celiac-superior mesenteric ganglion complex in a sham-operated rat $(\boldsymbol{E})$ and the complete absence of the ganglion complex in a ganglionectomized rat $(\boldsymbol{F})$. DA, Descending aorta; $C A$, celiac artery; MA, mesenteric artery. Filled arrows indicate the ganglion complex. ${ }^{*} p<0.05$ or $^{* *} p<0.01$ versus same surgical group; $p<0.05$ or ${ }^{\# \#} p<0.01$ versus sham-operated controls. Results are expressed as mean $\pm \mathrm{SEM} ; n=6 /$ condition.

monitoring sodium adducts of molecular ions in the SIM mode (Fu et al., 2007).

\section{Fatty acid amide hydrolase assay}

Jejunal tissue was homogenized and homogenates were centrifuged at $1000 \times g$ for $10 \mathrm{~min}$. Supernatants $(50 \mu \mathrm{g}$ of protein) were incubated with $\left[{ }^{3} \mathrm{H}\right]$-anandamide $(10,000 \mathrm{dpm}$, specific activity, $20 \mathrm{Ci} / \mathrm{mmol})$ for $30 \mathrm{~min}$ at $37^{\circ} \mathrm{C}$ in $0.5 \mathrm{ml}$ of $50 \mathrm{~mm}$ Tris- $\mathrm{HCl}$ buffer, $\mathrm{pH} \mathrm{8.0,} \mathrm{containing}$ fatty acid-free bovine serum albumin $(0.05 \% \mathrm{w} / \mathrm{v})$. Reactions were terminated adding $1.5 \mathrm{ml}$ of chloroform/methanol $(2: 1, \mathrm{v} / \mathrm{v})$ and phases were separated by centrifugation. The aqueous layers were collected and $\left[{ }^{3} \mathrm{H}\right]$-ethanolamine was quantified by liquid scintillation counting.

\section{Statistical analyses}

Results are expressed as the mean \pm SEM. The significance of differences between groups was evaluated by two-way ANOVA, followed by a Dunnett's test for multiple comparisons. Analyses were conducted using GraphPad Prism software (GraphPad Software), and differences were considered significant if $p<0.05$.

\section{Results}

\section{Sympathetic denervation abolishes food-induced}

\section{OEA mobilization}

As previously shown for intact rats (Fu et al., 2007; Schwartz et al., 2008), refeeding with standard rodent chow after a $24 \mathrm{~h}$ fast increased the levels of OEA (Fig. $2 A$ ) (two-way ANOVA, $F_{(1,20)}=$ 14.47, $p=0.001$ ) and its precursor NOPE (Fig. $2 B$ ) (two-way ANOVA, $\left.F_{(1,20)}=6.71, p=0.017\right)$ in jejunal tissue of shamoperated rats. Ex vivo measurements (Fu et al., 2007; Schwartz et al., 2008) showed that these effects are accompanied by an in- 
Table 1. Sympathetic denervation attenuates high-fat induced OEA (pmol/g tissue) mobilization in rat jejunum

\begin{tabular}{lll}
\hline & Sham & Ganglionectomy \\
\hline FD & $52.9 \pm 2.8$ & $52.2 \pm 2.6$ \\
RF & $85.0 \pm 6.0^{* * *}$ & $69.8 \pm 4.6^{* \#}$ \\
\hline
\end{tabular}

Sympathetic denervation attenuates high-fat-induced OEA mobilization in rat proximal small intestine. Thirty minutes of refeeding (RF) after $24 \mathrm{~h}$ of food deprivation in sham-operated animals increased jejunal OEA levels compared to food deprivation alone ( $F D ; * * 0<0.001)$. Jejunal OEA levels of ganglionectomized animals after refeeding are attenuated when compared to those in refeeding sham-operated animals $\left({ }^{*} p<0.05\right)$; however, ganglionectomy fails to completely block increases in OEA levels of refeeding animals versus those food-deprived $\left({ }^{\#} p<0.05\right)$. Results are expressed as mean \pm SEM; $n=6 /$ condition.

Table 2. Sympathetic denervation fails to affect body weights ( $\mathrm{g}$ ), and $30 \mathrm{~min}$ refeeding ( $\mathrm{g}$ ) of standard or high-fat chow, but increases average $24 \mathrm{~h}$ standard chow intakes $(\mathrm{g} / \mathrm{kg})$

\begin{tabular}{lllll}
\hline & Body weight & $24 \mathrm{~h}$ chow & Refeed standard & Refeed high-fat \\
\hline Sham & $294.2 \pm 4.0$ & $78.8 \pm 1.0$ & $5.0 \pm 0.5$ & $5.6 \pm 0.9$ \\
Ganglionectomy & $287.6 \pm 3.1$ & $82.8 \pm 1.2^{*}$ & $4.5 \pm 0.4$ & $5.1 \pm 0.2$ \\
\hline
\end{tabular}

Sympathetic denervation fails to affect body weights, or refeeding of standard or high-fat chow after a fast, but modestly increases $24 \mathrm{~h}$ intakes. Ganglionectomy failed to affect body weights, and refeeding of standard chow or a high-fat diet, when compared to sham-operated animals. A minor, but significant, increase in average $24 \mathrm{~h}$ intakes of standard chow was found in ganglionectomized animals versus sham-operated controls $\left({ }^{*} p<0.05\right)$. Results are expressed as mean $\pm \mathrm{SEM} ; n=6 /$ condition

crease in NAPE-PLD activity (Fig. $2 C$ ) (two-way ANOVA, $F_{(1,20)}=$ 6.03, $p=0.018$ ) and a decrease in fatty acid amide hydrolase $\left(\right.$ FAAH) activity (Fig. $2 D$ ) (two-way ANOVA, $F_{(1,20)}=11.11, p=$ 0.002 ). Surgical resection of the sympathetic celiac superior mesenteric ganglion, which extends projections to the upper gut (Lindh et al., 1988; Chevendra and Weaver, 1991; Parr et al., 1993; Furness et al., 2000), disabled food-dependent OEA mobilization in the jejunum (Fig. $2 \mathrm{~A}$ ). The surgical procedure markedly reduced OEA biosynthesis, preventing food-dependent changes in both NOPE production and NAPE-PLD activity (Fig. $2 B, C)$, and lowered FAAH activity in food-deprived animals (Fig. 2 D). Refeeding with a high-fat diet (60\% total kcal from fat) increased jejunal OEA levels in sham-operated rats (Table 1) (two-way ANOVA, $F_{(1,20)}=5.8, p=0.025$ ), as seen in animals refed with standard chow (Fig. $2 A$ ). Removal of the sympathetic ganglion attenuated, but did not completely block, this response (Table 1). The surgical procedure removed the ganglion complex in its entirety (Fig. $2 E, F$ ). In addition, we found no marked difference in standard chow or high-fat consumption and body weight between ganglionectomized and sham-operated animals, except for a minor, but significant, increase in free-feeding $24 \mathrm{~h}$ standard chow intakes (Table 2). The results suggest that the sympathetic nervous system serves an obligatory function in food-induced OEA mobilization.

\section{Role of $\boldsymbol{\beta}_{2}$-adrenergic receptors}

$\beta_{2}$-Adrenergic receptors are highly expressed in the rodent small intestine (Nasser et al., 2006). Pharmacological blockade of these receptors with the selective antagonist ICI-118,551 prevented food-induced OEA mobilization in rat jejunum (Fig. $3 A$ ) (twoway ANOVA, $\left.F_{(1,20)}=26.3, p=0001\right)$. Moreover, $\beta_{2}$-receptor blockade impaired the ability of refeeding to alter NOPE levels (Fig. $3 B$ ) (two-way ANOVA, $F_{(1,20)}=5.2, p=0.048$ ) and NAPEPLD activity (Fig. $3 C$ ) (two-way ANOVA, $F_{(1,20)}=6.84, p=$ 0.014 ) and reduced FAAH activity in food-deprived animals (Fig. $3 D$ ) (two-way ANOVA, $F_{(1,20)}=10.78, p=0.003$ ). Underscoring the pharmacological selectivity of these effects, systemic administration of drugs that antagonize other adrenergic receptorsincluding $\alpha$ (prazosin), $\beta_{1}$ (CGP2071), and $\beta_{3}$ (SR59230A) receptors-did not alter jejunal OEA mobilization (Table 3 ).
A
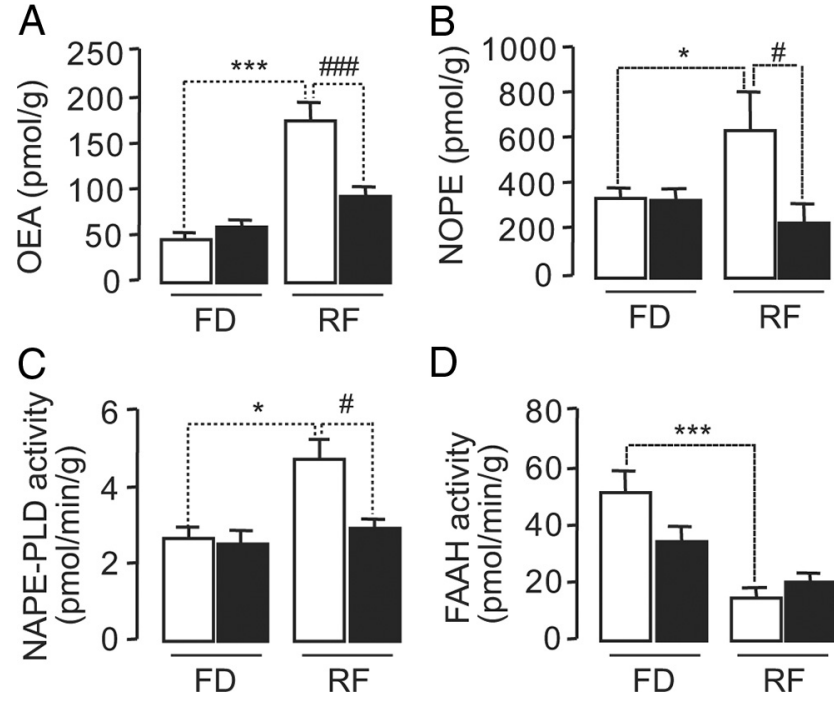

.

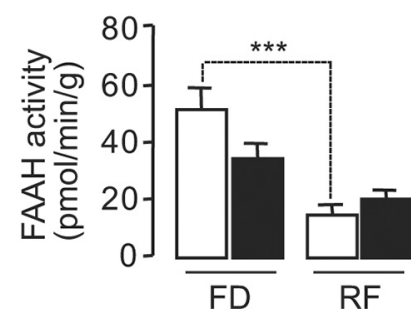

Figure 3. $\beta_{2}$-Adrenergic receptor blockade abolishes feeding-induced OEA mobilization in rat proximal small intestine. Effects of 30 min refeeding after $24 \mathrm{~h}$ food deprivation (RF) or food deprivation alone (FD) on jejunal levels of OEA $(\boldsymbol{A})$, NOPE $(\boldsymbol{B})$, NAPE-PLD activity $(\boldsymbol{C})$, and FAAH activity $(\boldsymbol{D})$ in vehicle-treated rats (open bars) or rats treated with the $\beta_{2}$ receptor antagonist ICl-118,551 (1 mg/kg, filled bars). ${ }^{*} p<0.05$ or ${ }^{* * *} p<0.01$ versus same treatment group; ${ }^{\#} p<0.05$ or ${ }^{\# \#} p<0.01$ versus sham-operated controls. Results are expressed as mean \pm SEM; $n=6 /$ condition.

Furthermore, systemic administration of adrenergic receptor agonists_including isoproterenol $(2.5,5$, and $10 \mathrm{mg} / \mathrm{kg})$, which targets $\beta_{1 /} \beta_{2}$ receptors, or salbutamol ( 1 and $5 \mathrm{mg} / \mathrm{kg}$ ), which preferentially targets $\beta_{2}$ receptors - exerted no detectable effect on jejunal OEA content under food-deprived conditions (Table 4 ). The same agonist dosages were found to markedly stimulate OEA production in rat white adipose tissue (LoVerme et al., 2006). We interpret these results to indicate that sympathetic activity facilitates small-intestinal OEA production, but is not sufficient to elicit this effect in the absence of food intake.

Sympathetic activity controls blood levels of NPPE and NOPE Refeeding after a $24 \mathrm{~h}$ fast increased plasma NPPE levels in shamoperated rats, as previously shown for intact rats (Gillum et al., 2008) (Fig. 4A) (two-way ANOVA, $F_{(1,20)}=12.56, p=0.004$ ). This response was greatly reduced in rats in which the celiac superior mesenteric ganglion had been removed (Fig. 4A) or which had received an injection of the $\beta_{2}$-adrenergic antagonist ICI-118,551(1 mg/kg) $30 \mathrm{~min}$ before food exposure (Fig. $4 B$ ) (two-way ANOVA, $F_{(1,20)}=12.00, p=0.0032$ ). Similar results were obtained with the OEA precursor, NOPE, in those receiving surgery (Fig. 4C) (two-way ANOVA, $F_{(1,20)}=12.36, p=0.0015$ ) or pharmacological treatment (Fig. $4 D$ ) (two-way ANOVA, $\left.F_{(1,20)}=7.83, p=0.01\right)$. Notably, in contrast with a previous report (Gillum et al., 2008), we found that both baseline and food-stimulated NOPE levels in plasma were significantly higher than corresponding NPPE levels (Fig. 4). We conclude that sympathetic neural activity controls, through activation of $\beta_{2}$ adrenergic receptors, the release of both NPPE and NOPE into the general circulation.

\section{Sympathetic denervation modifies meal patterns}

OEA modifies food intake by reducing daily meal frequency, and increasing satiety ratio [ratio between average PMI and meal size (Gaetani et al., 2003)]. Free-feeding ganglionectomized animals displayed increases in average $24 \mathrm{~h}$ meal frequency (Fig. 5A1), 
Table 3. Effect of $\boldsymbol{\alpha}^{-}, \boldsymbol{\beta}_{1^{-}}$, or $\boldsymbol{\beta}_{3}$-adrenergic receptor antagonists on intestinal OEA levels (pmol/g)

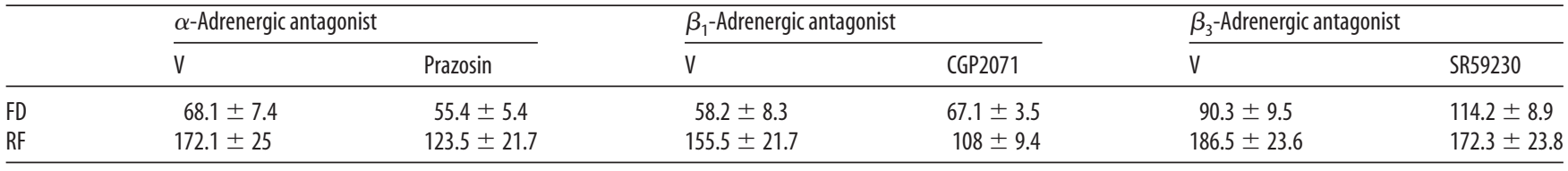

Administration of $\alpha-, \beta_{1}$, or $\beta_{3}$-adrenergic receptor antagonists does not affect jejunal OEA levels in refed rats. Thirty minutes of refeeding (RF) after $24 \mathrm{~h}$ of food deprivation in vehicle (V)-treated animals increased jejunal 0 EA levels compared to $24 \mathrm{~h}$ food deprivation alone (FD). Systemic treatment with $\alpha$ - (prazosin), $\beta_{1}$ - (CGP2071), or $\beta_{3}$ - (SR59230A) adrenergic receptor antagonists did not alter 0EA mobilization. Results are expressed as mean \pm SEM; $n=$ 6/condition.

Table 4. $\beta$-Adrenergic receptor agonists do not affect intestinal OEA levels (pmol/g)

\begin{tabular}{|c|c|c|c|c|c|c|c|}
\hline & \multirow[b]{3}{*}{ Free-feed } & \multicolumn{6}{|c|}{ Food deprivation } \\
\hline & & \multirow[b]{2}{*}{ Saline } & \multicolumn{3}{|c|}{ Isoproterenol (mg/kg) } & \multicolumn{2}{|c|}{ Salbutamol ( $\mu \mathrm{g} / \mathrm{kg})$} \\
\hline & & & 2.5 & 5 & 10 & 1 & 5 \\
\hline OEA & $213.8 \pm 25.2$ & $93.4 \pm 1.6$ & $113.2 \pm 26.5$ & $127.4 \pm 43.4$ & $105.7 \pm 22.9$ & $83.4 \pm 14.9$ & $77.8 \pm 5.6$ \\
\hline
\end{tabular}
jejunal levels of $O E A$ in food-deprived animals when compared to saline-treated controls. Results are expressed as mean $\pm \mathrm{SEM} ; n=6 /$ condition.
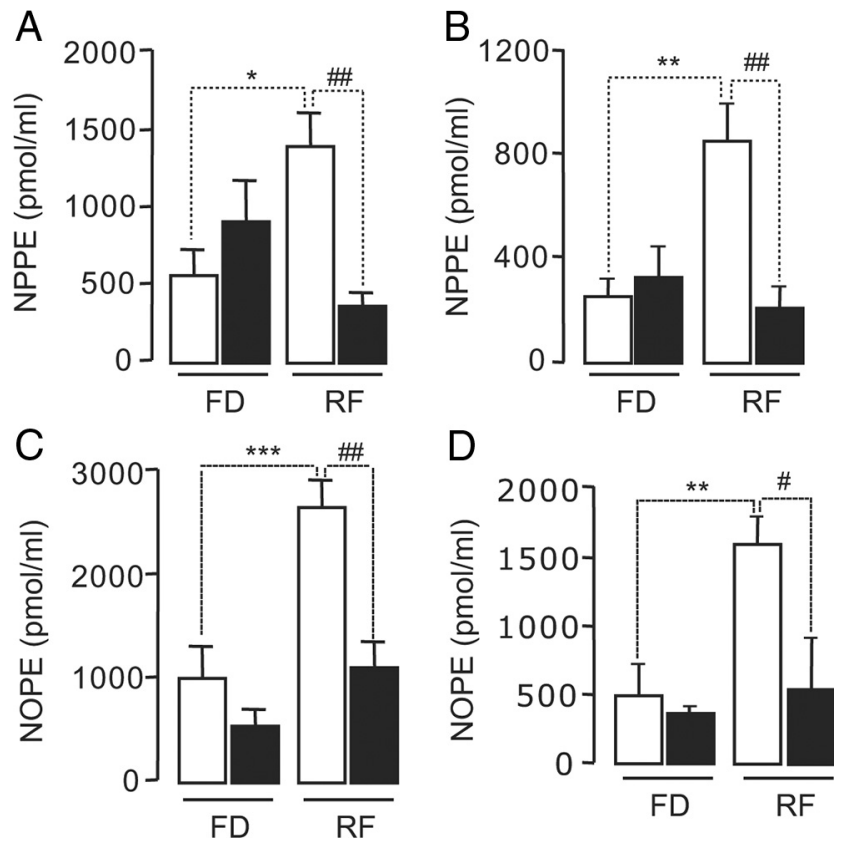

Figure 4. Sympathetic denervation lowers feeding-induced NPPE and NOPE levels in rat plasma. Effects of $30 \mathrm{~min}$ refeeding after $24 \mathrm{~h}$ food deprivation (RF) or food deprivation alone (FD) on plasma levels of NPPE $(\boldsymbol{A})$ and NOPE (C) in sham-operated (open bars) or ganglionectomized (filled bars) rats. Effects of 30 min refeeding after $24 \mathrm{~h}$ food deprivation (RF) or food deprivation alone (FD) on plasma levels of NPPE $(\boldsymbol{B})$ and NOPE $(\boldsymbol{D})$ in vehicle-treated rats (open bars) or rats treated with the $\beta_{2}$ receptor antagonist ICI-118,551 (1 mg/kg, filled bars). ${ }^{*} p<$ $0.05,{ }^{* *} p<0.01$, or ${ }^{* * *} p<0.001$ versus the same surgical or treatment group; ${ }^{*} p<0.05$ or ${ }^{\# \#} p<0.01$ versus sham-operated controls or those treated with vehicle. Results are expressed as mean $\pm \mathrm{SEM} ; n=6 /$ condition.

and decreases in average meal size (Fig. 5A2), average PMI (Fig. $5 A 3$ ), and average satiety ratio (Fig. $5 A 4$ ), versus sham-operated controls. Treatment with an effective dose of OEA [10 mg/kg, i.p., at time of dark onset (Gaetani et al., 2003)] completely normalized all daily free-feeding parameters affected by ganglionectomy (Fig. 5B1-B4). Ganglionectomized animals refed after a $24 \mathrm{~h}$ fast displayed greater average meal frequencies (Fig. $5 \mathrm{Cl}$ ), and decreased average PMI (Fig. 5C3) and average satiety ratio (Fig. $5 C 4$ ), versus sham-operated controls. We found no statistically significant changes in average meal size (Fig. 5C2). The results indicate that, under conditions where OEA signaling is disrupted by ganglionectomy, normal meal patterns controlled by OEA become aberrant.

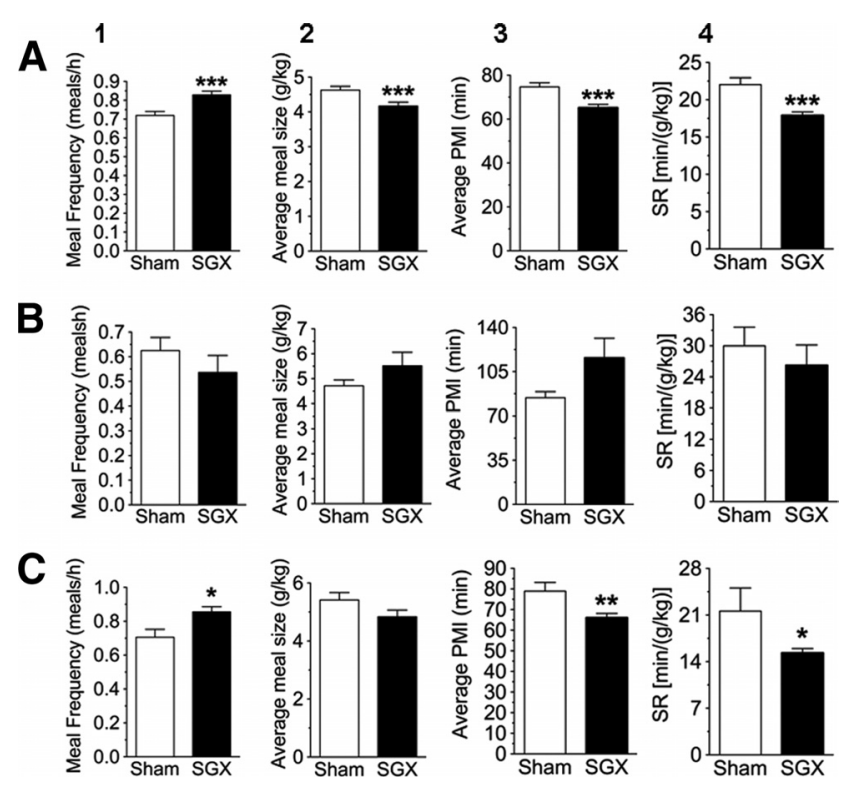

Figure 5. Sympathetic denervation alters feeding behavior. Effects of sham operation (open bars) and ganglionectomy (filled bars) in free-feeding animals, on $5 \mathrm{~d}$ averages of meal frequency $(\boldsymbol{A} 1)$, meal size $(\boldsymbol{A 2})$, PMI (A3), and SR (A4). Effects of OEA treatment in free-feeding ganglionectomized animals (filled bars) and vehicle treatment in sham-operated controls (open bars) on average $24 \mathrm{~h}$ meal frequency (B1), meal size (B2), PMI (B3), and SR (B4). Effects of sham operation (open bars) and ganglionectomy (filled bars), in animals refed after $24 \mathrm{~h}$ food deprivation, on average $24 \mathrm{~h}$ meal frequency $(\mathbf{C 1})$, meal size (C2), PMI (C3), and SR (C4). Vh, Vehicle; OEA, $10 \mathrm{mg} / \mathrm{kg}$ (i.p.); Sham, sham operation; SGX, celiac-superior mesenteric ganglionectomy. ${ }^{*} p<0.05,{ }^{* *} p<0.01$, or ${ }^{* * *} p<0.001$ versus sham-operated controls. Results are expressed as mean \pm SEM. Sham operation, $n=9$; ganglionectomy, $n=10$.

\section{Discussion}

Dietary fat stimulates enterocytes in the proximal small intestine to produce the endogenous lipid amide, OEA, which may regulate satiety through a local autocrine or paracrine mechanism (Rodríguez de Fonseca et al., 2001; Fu et al., 2003; Schwartz et al., 2008). Consistent with this view, systemic administration of OEA inhibits food intake in rodents, and this effect is (1) prevented by treatment with the sensory-fiber neurotoxin capsaicin (Rodríguez de Fonseca et al., 2001); and (2) mimicked by virally induced overexpression of NAPE-PLD in the small intestine, which locally elevates tissue OEA levels (Fu et al., 2008), but not by infusion of OEA into the brain ventricles (Rodríguez de Fonseca et al., 2001). These findings suggest that OEA regulates feeding by recruiting 
sensory vagal afferents in the gut. In further support of this possibility, OEA increases expression of c-Fos (a marker of neuronal activation) in the nucleus of the solitary tract of the brainstem and in the paraventricular and supraoptic nuclei of the hypothalamus, which receive direct and indirect neural inputs from the sensory vagus (Rodríguez de Fonseca et al., 2001). Furthermore, systemic administration of OEA stimulates expression of the hypothalamic neuropeptide oxytocin, and intracerebroventricular infusion of an oxytocin receptor antagonist prevents OEA-induced hypophagia (Gaetani et al., 2010). These studies collectively suggest that small-intestinal fluctuations in OEA mobilization regulate satiety by triggering the central release of oxytocin through the sensory vagus (Gaetani et al., 2010). Similarly to OEA, NPPE inhibits food intake and stimulates c-Fos expression in the paraventricular and supraoptic nuclei of the hypothalamus (Gillum et al., 2008). However, the effects of systemic NPPE administration are not altered by subdiaphragmatic vagotomy and are reproduced by intracerebroventricular infusion of NPPE, suggesting that this compound may reach its target sites in the brain through the general circulation (Gillum et al., 2008). Thus, a plausible interpretation of the available data is that dietary fat stimulates small intestinal cells to generate mediators that act both locally (OEA) and systemically (NPPE) to modulate satiety responses.

In the present study, we have shown that (1) surgical removal of the sympathetic innervation of the gut prevents the foodinduced mobilization of OEA and NPPE; (2) this effect is mimicked by pharmacological blockade of $\beta_{2}$-adrenergic receptors, but not by administration of other adrenergic receptor antagonists; (3) $\beta_{2}$-adrenergic agonists fail to stimulate OEA mobilization when administered alone to food-deprived animals; and (4) sympathetic ganglionectomy alters meal patterns that are under the control of OEA. These results indicate that fat-induced signaling through OEA and NPPE, although primarily regulated by dietary fat ingestion, is subjected to the integrative control of the sympathetic nervous system.

The sympathetic nervous system plays a key function in the control of energy balance (Berthoud, 2008; Lambert et al., 2010). Current research is primarily focused on the role played by this system in peripheral glucose and lipid metabolism (Haque et al., 1999; Bartness et al., 2005; Nogueiras et al., 2007, 2009; Shiuchi et al., 2009), yet the existence of links between feeding state and sympathetic activity has long been recognized. Early work by Young and Landsberg has shown that fasting is associated with a decrease in sympathetic outflow (Young and Landsberg, 1977a), whereas sucrose feeding and chronic feeding of lard are accompanied by an increase in sympathetic outflow (Young and Landsberg, 1977b; Young et al., 1994). These changes parallel those undergone by small-intestinal OEA, the levels of which also decrease during fasting and increase during refeeding (Fu et al., 2003; Fu et al., 2007; present study). More recently, Sclafani et al. (2003) found that surgical ablation of the celiac superior mesenteric ganglion complex- the same intervention used here to remove sympathetic innervation of the gut - prevents the satiating actions of duodenal fat infusion. These observations are consistent with the findings in this report, and raise the intriguing possibility that sympathetic activity modulates satiety in response to fat by facilitating fat-dependent OEA and NPPE signaling in the small intestine.

An important question that remains to be addressed pertains to the mechanism through which sympathetic activity facilitates small-intestinal OEA biosynthesis. Postganglionic-sympathetic efferents targeting the intestine terminate in the submucosal and myenteric plexus (Nasser et al., 2006; Lomax et al., 2010), but do not reach the enterocytes where OEA is synthesized (Fu et al., 2007; Schwartz et al., 2008). In addition, $\beta_{2}$ receptors are localized to enteric neurons in the submucosal and myenteric plexus of the rodent intestine, which implies that adrenergic activity controls enterocyte OEA biosynthesis through an indirect mechanism (e.g., a diffusible factor or reflexes mediated by the enteric nervous system). Despite these uncertainties, our results, showing that both blockade of $\beta_{2}$ receptors and ganglionectomy abolish feeding-induced OEA biosynthesis, clearly identify a postganglionic sympathetic involvement in this response.

\section{References}

Astarita G, Geaga J, Ahmed F, Piomelli D (2009) Targeted lipidomics as a tool to investigate endocannabinoid function. Int Rev Neurobiol 85: $35-55$.

Bartness TJ, Kay Song C, Shi H, Bowers RR, Foster MT (2005) Brainadipose tissue cross talk. Proc Nutr Soc 64:53-64.

Berthoud HR (2008) The vagus nerve, food intake and obesity. Regul Pept 149:15-25.

Chevendra V, Weaver LC (1991) Distribution of splenic, mesenteric and renal neurons in sympathetic ganglia in rats. J Auton Nerv Syst 33:47-53.

Fu J, Gaetani S, Oveisi F, Lo Verme J, Serrano A, Rodríguez de Fonseca F, Rosengarth A, Luecke H, Di Giacomo B, Tarzia G, Piomelli D (2003) Oleylethanolamide regulates feeding and body weight through activation of the nuclear receptor PPAR-alpha. Nature 425:90-93.

Fu J, Astarita G, Gaetani S, Kim J, Cravatt BF, Mackie K, Piomelli D (2007) Food intake regulates oleoylethanolamide formation and degradation in the proximal small intestine. J Biol Chem 282:1518-1528.

Fu J, Kim J, Oveisi F, Astarita G, Piomelli D (2008) Targeted enhancement of oleoylethanolamide production in proximal small intestine induces across-meal satiety in rats. Am J Physiol Regul Integr Comp Physiol 295:R45-R50.

Furness JB, Koopmans HS, Robbins HL, Lin HC (2000) Identification of intestinofugal neurons projecting to the coeliac and superior mesenteric ganglia in the rat. Auton Neurosci 83:81-85.

Gaetani S, Oveisi F, Piomelli D (2003) Modulation of meal pattern in the rat by the anorexic lipid mediator oleoylethanolamide. Neuropsychopharmacology 28:1311-1316.

Gaetani S, Fu J, Cassano T, Dipasquale P, Romano A, Righetti L, Cianci S, Laconca L, Giannini E, Scaccianoce S, Mairesse J, Cuomo V, Piomelli D (2010) The fat-induced satiety factor oleoylethanolamide suppresses feeding through central release of oxytocin. J Neurosci 30:8096-8101.

Gillum MP, Zhang D, Zhang XM, Erion DM, Jamison RA, Choi C, Dong J, Shanabrough M, Duenas HR, Frederick DW, Hsiao JJ, Horvath TL, Lo CM, Tso P, Cline GW, Shulman GI (2008) N-acylphosphatidylethanolamine, a gut- derived circulating factor induced by fat ingestion, inhibits food intake. Cell 135:813-824.

Giuffrida A, Rodríguez de Fonseca F, Piomelli D (2000) Quantification of bioactive acylethanolamides in rat plasma by electrospray mass spectrometry. Anal Biochem 280:87-93.

Haque MS, Minokoshi Y, Hamai M, Iwai M, Horiuchi M, Shimazu T (1999) Role of the sympathetic nervous system and insulin in enhancing glucose uptake in peripheral tissues after intrahypothalamic injection of leptin in rats. Diabetes 48:1706-1712.

Lambert GW, Straznicky NE, Lambert EA, Dixon JB, Schlaich MP (2010) Sympathetic nervous activation in obesity and the metabolic syndromecauses, consequences and therapeutic implications. Pharmacol Ther 126:159-172.

Lindh B, Hökfelt T, Elfvin LG (1988) Distribution and origin of peptidecontaining nerve fibers in the celiac superior mesenteric ganglion of the guinea-pig. Neuroscience 26:1037-1071.

Lomax AE, Sharkey KA, Furness JB (2010) The participation of the sympathetic innervation of the gastrointestinal tract in disease states. Neurogastroenterol Motil 22:7-18.

LoVerme J, Guzmán M, Gaetani S, Piomelli D (2006) Cold exposure stimulates synthesis of the bioactive lipid oleoylethanolamide in rat adipose tissue. J Biol Chem 281:22815-22818.

Nasser Y, Ho W, Sharkey KA (2006) Distribution of adrenergic receptors in the enteric nervous system of the guinea pig, mouse, and rat. J Comp Neurol 495:529-553.

Nogueiras R, Wiedmer P, Perez-Tilve D, Veyrat-Durebex C, Keogh JM, Sut- 
ton GM, Pfluger PT, Castaneda TR, Neschen S, Hofmann SM, Howles PN, Morgan DA, Benoit SC, Szanto I, Schrott B, Schürmann A, Joost HG, Hammond C, Hui DY, Woods SC, et al. (2007) The central melanocortin system directly controls peripheral lipid metabolism. J Clin Invest 117:3475-3488.

Nogueiras R, Pérez-Tilve D, Veyrat-Durebex C, Morgan DA, Varela L, Haynes WG, Patterson JT, Disse E, Pfluger PT, López M, Woods SC, DiMarchi R, Diéguez C, Rahmouni K, Rohner-Jeanrenaud F, Tschöp MH (2009) Direct control of peripheral lipid deposition by CNS GLP-1 receptor signaling is mediated by the sympathetic nervous system and blunted in diet-induced obesity. J Neurosci 29:5916-5925.

Parr EJ, Davison SN, Davison JS, Sharkey KA (1993) The origin and distribution of neurons with projections passing through the inferior mesenteric ganglion of the guinea-pig. J Auton Nerv Syst 44:91-99.

Proulx K, Cota D, Castañeda TR, Tschöp MH, D’Alessio DA, Tso P, Woods SC, Seeley RJ (2005) Mechanisms of oleoylethanolamide-induced changes in feeding behavior and motor activity. Am J Physiol Regul Integr Comp Physiol 289:R729-R737.

Rodríguez de Fonseca F, Navarro M, Gómez R, Escuredo L, Nava F, Fu J, Murillo-Rodríguez E, Giuffrida A, LoVerme J, Gaetani S, Kathuria S, Gall
C, Piomelli D (2001) An anorexic lipid mediator regulated by feeding. Nature 414:209-212.

Schwartz GJ, Fu J, Astarita G, Li X, Gaetani S, Campolongo P, Cuomo V, Piomelli D (2008) The lipid messenger OEA links dietary fat intake to satiety. Cell Metab 8:281-288.

Sclafani A, Ackroff K, Schwartz GJ (2003) Selective effects of vagal deafferentation and celiac-superior mesenteric ganglionectomy on the reinforcing and satiating action of intestinal nutrients. Physiol Behav 78:285-294.

Shiuchi T, Haque MS, Okamoto S, Inoue T, Kageyama H, Lee S, Toda C, Suzuki A, Bachman ES, Kim YB, Sakurai T, Yanagisawa M, Shioda S, Imoto K, Minokoshi Y (2009) Hypothalamic orexin stimulates feedingassociated glucose utilization in skeletal muscle via sympathetic nervous system. Cell Metab 10:466-480.

Young JB, Landsberg L (1977a) Suppression of sympathetic nervous system during fasting. Science 196:1473-1475.

Young JB, Landsberg L (1977b) Stimulation of the sympathetic nervous system during sucrose feeding. Nature 269:615-617.

Young JB, Daly PA, Uemura K, Chaouloff F (1994) Effects of chronic lard feeding on sympathetic nervous system activity in the rat. Am J Physiol 267:R1320-R1328. 